\section{Effects of Dietary Green Tea Polyphenol Supplementation on the Health of Workers Exposed to High-voltage Power Lines}

\author{
Eslami J. ${ }^{10}$, Mortazavi Gh. ${ }^{2}$, Mortazavi S. A. R. ${ }^{3}$, Paknahad \\ M. ${ }^{4 *(1)}$
}

\section{Dear Editor,}

This letter considers an article by Yang Zhang et al. entitled "Effects of dietary green tea polyphenol supplementation on the health of workers exposed to high-voltage power lines" published in the Journal of Environmental Toxicology and Pharmacology http://dx.doi. org/10.1016/j.etap.2016.07.016 [1]. Yang Zhang et al. investigated the change in oxidative stress level after exposure to extremely low-frequency electromagnetic fields (ELF-EMFs), and the potential protective effects of green tea polyphenol supplementation (GTPS) on ELF-EMFs induced oxidative stress. Authors showed an increased urinary 8-isoprostane and $8-\mathrm{OHdG}$ among workers with ELF-EMFs exposure, and demonstrated that long-term GTPS could be an efficient protection against the health issues induced by high-voltage power lines. Our laboratory researchers at Non-ionizing Department of Ionizing and Nonionizing Radiation Protection Research Center (INIRPRC) have performed experiments on the health effects of exposure to different sources of electromagnetic fields such as cellular phones [2-13], mobile base stations [14], mobile phone jammers $[15,16]$, laptop computers [17], radars [3], dentistry Cavitrons [18], MRI [8-19] and Helmholtz coils [20, 21]. Although the paper authored by Zhang et al. is a well-structured informative article, it has some shortcomings. The first shortcoming of this paper comes from the point that the authors have paid attention to minor confounding factors such as computer use time, but they have simply ignored the key role of exposure to some widely used sources of EMFs such as cordless phones, mobile phone base stations and Wi-Fi connected devices (e.g. tablets, laptops and smartphones). The authors, unfortunately, did not pay attention to the fact that in today's modern life, mobile phones are much more frequently used for texting (exchanging messages) and Internet surfing than calling.

Furthermore, the oxidative stress induced by electromagnetic fields cannot be interpreted as a $100 \%$ negative phenomenon under all circumstances. The induction of adaptive responses by pre-exposure to both ionizing and non-ionizing radiations is well documented by different researchers as well as our research team [6, 22-25]. The adaptive response can be defined as withstanding the stress of a subsequent exposure to higher doses of radiation and/or chemicals after pre-exposure to low doses of the same agent. Based on the findings of our studies, we believe that low-level oxidative stress is a phenomenon that serves as a bridge linking the radio-adaptive responses induced by ionizing radiation to those induced by non-ionizing radiation. Moreover, we have previously discussed that under special circumstances, exposure to mobile phone radiation can lead to some beneficial phenomena or a better response of humans to different hazards [26-29].

Citation: Eslami J, Mortazavi Gh, Mortazavi S. A. R, Paknahad M. Effects of Dietary Green Tea Polyphenol Supplementation on the Health of Workers Exposed to High-voltage Power Lines. J Biomed Phys Eng. 2019;9(3):257-258. https://doi.org/10.31661/jbpe.v9i3Jun.664.

\section{References}

1. Zhang Y, Zhang D, Zhu B, Zhang H, Sun Y, Sun C. Effects of dietary green tea polyphenol supplementation on the health of workers exposed to high-voltage power lines. Environ Toxicol Pharmacol. 2016;46:183-7. doi.org/10.1016/j.etap.2016.07.016. PubMed PMID: 27490209.

2. Mortazavi SM, Motamedifar M, Namdari G, Taheri M, Mortazavi AR, Shokrpour N. Non-linear adaptive phenomena which decrease the risk of infection after pre-exposure to radiofrequency radiation. Dose Response. 2014;12:233-45. doi.org/10.2203/dose-response.12-055.Mortazavi. PubMed PMID: 24910582. PubMed PMCID: 4036396.

3. Mortazavi SM, Taeb S, Dehghan N. Alterations of visual reaction time and short term memory in military radar personnel. Iran J Public Health. 2013;42:428-35. PubMed PMID: 23785684. PubMed PMCID: 3684731.

4. Mortazavi SM, Rouintan MS, Taeb S, Dehghan N, Ghaffarpanah AA, Sadeghi Z, et al. Human short-
${ }^{1}$ Anesthesiology Department, School of Nurs-

ing, Shiraz University

of Medical Sciences,

Shiraz, Iran

${ }^{2}$ Ionizing and Non-ioniz-

ing Radiation Protection

Research Center (INIR-

PRC), Shiraz University

of Medical Sciences,

Shiraz, Iran

${ }^{3}$ Medical Student,

Student Research Com-

mittee, Shiraz University

of Medical Sciences,

Shiraz, Iran

${ }^{4}$ Assistant Professor

of Dentomaxillofacial

Radiology, School of

Dentistry, Shiraz Univer-

sity of Medical Sciences,

Shiraz, Iran

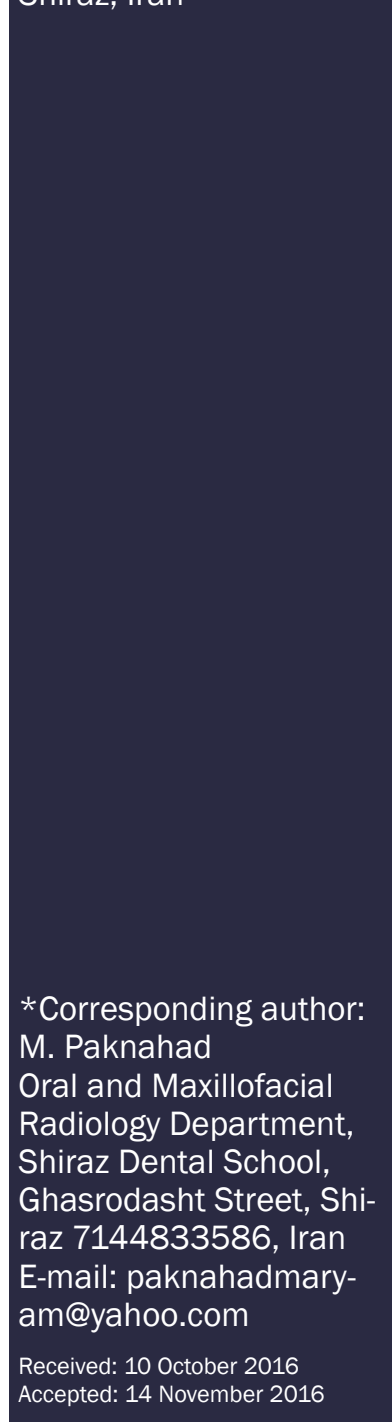


term exposure to electromagnetic fields emitted by mobile phones decreases computer-assisted visual reaction time. Acta Neurol Belg. 2012;112:171-5. doi.org/10.1007/s13760-0120044-y. PubMed PMID: 22426673.

5. Mortazavi S, Mosleh-Shirazi M, Tavassoli A, Taheri M, Mehdizadeh A, Namazi S, et al. Increased Radioresistance to Lethal Doses of Gamma Rays in Mice and Rats after Exposure to Microwave Radiation Emitted by a GSM Mobile Phone Simulator. Dose Response. 2013;11:281-92. doi.org/10.2203/dose-response.12-010.Mortazavi. PubMed PMID: 23930107. PubMed PMCID: 3682203.

6. Mortazavi S, Mosleh-Shirazi M, Tavassoli A, Taheri M, Bagheri Z, Ghalandari R, et al. A comparative study on the increased radioresistance to lethal doses of gamma rays after exposure to microwave radiation and oral intake of flaxseed oil. Iranian Journal of Radiation Research. 2011;9:9-14.

7. Mortavazi S, Habib A, Ganj-Karami A, Samimi-Doost R, PourAbedi A, Babaie A. Alterations in TSH and Thyroid Hormones following Mobile Phone Use. Oman Med J. 2009;24:274-8. doi. org/10.5001/omj.2009.56.

8. Mortazavi SM, Daiee E, Yazdi A, Khiabani K, Kavousi A, Vazirinejad $R$, et al. Mercury release from dental amalgam restorations after magnetic resonance imaging and following mobile phone use. Pak J Biol Sci. 2008;11:1142-6. doi.org/10.3923/ pjbs.2008.1142.1146. PubMed PMID: 18819554

9. Mortazavi SM, Ahmadi J, Shariati M. Prevalence of subjective poor health symptoms associated with exposure to electromagnetic fields among university students. Bioelectromagnetics. 2007;28:326-30. doi.org/10.1002/bem.20305. PubMed PMID: 17330851.

10. Mortazavi S, Motamedifar M, Namdari G, Taheri M, Mortazavi A. Counterbalancing immunosuppression-induced infections during long-term stay of humans in space. Journal of Medical Hypotheses and Ideas. 2013;7:8-10. doi.org/10.1016/j. jmhi.2012.12.001.

11. Mortazavi G, Haghani M, Rastegarian N, Zarei S, Mortazavi SM. Increased Release of Mercury from Dental Amalgam Fillings due to Maternal Exposure to Electromagnetic Fields as a Possible Mechanism for the High Rates of Autism in the Offspring: Introducing a Hypothesis. J Biomed Phys Eng. 2016;6:41-6. PubMed PMID: 27026954. PubMed PMCID: 4795328.

12. Mortazavi G, Mortazavi SM. Increased mercury release from dental amalgam restorations after exposure to electromagnetic fields as a potential hazard for hypersensitive people and pregnant women. Rev Environ Health. 2015;30:287-92. doi. org/10.1515/reveh-2015-0017. PubMed PMID: 26544100.

13. Mortazavi SM, Atefi M, Kholghi F. The pattern of mobile phone use and prevalence of self-reported symptoms in elementary and junior high school students in shiraz, iran. Iran J Med Sci. 2011;36:96-103. PubMed PMID: 23358105. PubMed PMCID: 3556746.

14. Mortazavi S. Safety issue of mobile phone base stations. J Biomed Phys Eng. 2013;3:1-2.

15. Parsanezhad M, Mortazavi S, Doohandeh T, Jahromi BN, Mozdarani $\mathrm{H}$, Zarei $\mathrm{A}$, et al. Exposure to radiofrequency radiation emitted from mobile phone jammers adversely affects the quality of human sperm. International Journal of Radiation Research. 2015.

16. Mortazavi S, Parsanezhad M, Kazempour M, Ghahramani $P$, Mortazavi A, Davari M. Male reproductive health under threat: Short term exposure to radiofrequency radiations emitted by common mobile jammers. J Hum Reprod Sci. 2013;6:1248. doi.org/10.4103/0974-1208.117178. PubMed PMID: 24082653. PubMed PMCID: 3778601.
17. Mortazavi SMJ, Tavassoli A, Ranjbari F, Moammaiee P. Effects of laptop computers' electromagnetic field on sperm quality. Journal of Reproduction \& Infertility. 2010;11(4).

18. Mortazavi SM, Vazife-Doost S, Yaghooti M, Mehdizadeh S, Rajaie-Far A. Occupational exposure of dentists to electromagnetic fields produced by magnetostrictive cavitrons alters the serum cortisol level. J Nat Sci Biol Med. 2012;3:60-4. doi. org/10.4103/0976-9668.95958. PubMed PMID: 22690053. PubMed PMCID: 3361780.

19. Mortazavi SM, Neghab M, Anoosheh SM, Bahaeddini N, Mortazavi G, Neghab P, et al. High-field MRI and mercury release from dental amalgam fillings. Int J Occup Environ Med. 2014;5:101-5. PubMed PMID: 24748001.

20. Haghnegahdar A, Khosrovpanah H, Andisheh-Tadbir A, Mortazavi G, Saeedi Moghadam M, Mortazavi S, et al. Design and fabrication of helmholtz coils to study the effects of pulsed electromagnetic fields on the healing process in periodontitis: preliminary animal results. J Biomed Phys Eng. 2014:4:83-90. PubMed PMID: 25505775. PubMed PMCID: 4258865.

21. Paknahad M, Shahidi S, Mortazavi SMJ, Mortazavi G, Moghadam MS, Nazhvani AD. The Effect of Pulsed Electromagnetic Fields on Microleakage of Amalgam Restorations: An in Vitro Study. Shiraz E-Medical Journal. 2016;17:e32329.

22. Mortazavi S, Mosleh-Shirazi M, Tavassoli A, Taheri M, Mehdizadeh A, Namazi S, et al. Increased Radioresistance to Lethal Doses of Gamma Rays in Mice and Rats after Exposure to Microwave Radiation Emitted by a GSM Mobile Phone Simulator. Dose Response. 2013;11:281-92. doi.org/10.2203/dose-response.12-010.Mortazavi. PubMed PMID: 23930107. PubMed PMCID: 3682203.

23. Sannino A, Sarti M, Reddy SB, Prihoda TJ, Vijayalaxmi, Scarfi MR. Induction of adaptive response in human blood lymphocytes exposed to radiofrequency radiation. Radiat Res. 2009;171:735-42. doi.org/10.1667/RR1687.1. PubMed PMID: 19580480.

24. Ghiassi-Nejad M, Beitollahi M, Fujinami N, Morishima H, editors. Radiological parameters of a house with high levels of natural radiation, Ramsar, Iran. International Congress Series; 2002: Elsevier.

25. Mortazavi S, Karam P. Apparent lack of radiation susceptibility among residents of the high background radiation area in Ramsar, Iran: can we relax our standards? Radioactivity in the Environment. 2005;7:1141-7. doi.org/10.1016/S15694860(04)07140-2.

26. Mortazavi SA, Tavakkoli-Golpayegani A, Haghani M, Mortazavi SM. Looking at the other side of the coin: the search for possible biopositive cognitive effects of the exposure to $900 \mathrm{MHz}$ GSM mobile phone radiofrequency radiation. J Environ Health Sci Eng. 2014;12:75. doi.org/10.1186/2052-336X-12-75. PubMed PMID: 24843789. PubMed PMCID: 4004454.

27. Mortazavi S, Mortazavi S. Is mobile phone radiofrequency radiation all bad. J Med Hypotheses Ideas. 2014;8:42-3. doi. org/10.1016/j.jmhi.2013.08.003.

28. Eghlidospour M, Mortazavi SM, Yousefi F, Mortazavi SA. New Horizons in Enhancing the Proliferation and Differentiation of Neural Stem Cells Using Stimulatory Effects of the Short Time Exposure to Radiofrequency Radiation. J Biomed Phys Eng. 2015;5:95-104. PubMed PMID: 26396965. PubMed PMCID: 4576878.

29. Mortazavi S, Shojaei-Fard M, Haghani M, Shokrpour N. Exposure to mobile phone radiation opens new horizons in Alzheimer's disease treatment. J Biomed Phys Eng. 2013;3:109-12. PubMed PMID: 25505755. PubMed PMCID: 4204502. 